NASZA DERMATOLOGIA Online OUR DERMATOLOGY Online Nil

Competing Interests: None

\section{TRANSIENT CUTANEOUS HYPERPIGMENTATION OF EXTREMITIES FOLLOWING DENGUE FEVER}

\author{
Shrikiran Aroor, Sandeep Kumar, Suneel Mundkur \\ Department of Pediatrics, Kasturba Medical College, Manipal University, Manipal, \\ India
}

Corresponding author: Dr Sandeep Kumar, MD

bksandydoc@gmail.com
A 14 year old boy presented with fever and generalized flushing of skin of 1 week duration. His vital signs were normal. Examination revealed generalized blanching macular erythematous rash. Systemic examination was unremarkable except for tender hepatomegaly. Investigations revealed leucopenia, thrombocytopenia and normal hemoglobin with mildly elevated liver transaminases. NS 1 (Non-structural protein-1) antigen and IgM antibody titer for Dengue ELISA was positive suggesting dengue fever. He was managed symptomatically and he recovered. During his follow up after 2 weeks he presented with brownish discoloration of dorsum of both hands and feet. There was no history of intake of any medication. Examination revealed symmetrical striking macular hyperpigmentation involving dorsum of extremities predominantly over the distal interphalangeal joints (Figs. 1, 2). His general physical and systemic examination was normal. His repeat blood counts, renal function tests, liver function tests and serum cortisol levels were normal. Vitamin B12 levels were normal and IgM antibody titre for chikungunya was negative. Workup for HIV and porphyria was negative. Parents were reassured and gradual disappearance of lesions was noticed over next 8 weeks.

Cutaneous hyperpigmentation is known to be associated with a variety of systemic disorders which include endocrinapathies such as Addison's disease, Nelson syndrome, metabolic diseases such as Wilson's disease, Fanconi 's anemia, hemochromatosis and nutritional deficiencies mainly vitamin B12 [1]. Many drugs have been implicated in causing skin pigmentation including nonsteroidal anti-inflammatory drugs, antimalarials, amiodarone, cytotoxic drugs, and heavy metals [2]. Viral exanthematous illnesses are also known to cause hyperpigmented lesions, where etiology appears to be post inflammatory. Both diffuse and focal hyperpigmentation predominantly involving centrofacial area has been described in patients with chikungunya fever during the recovery phase [3].

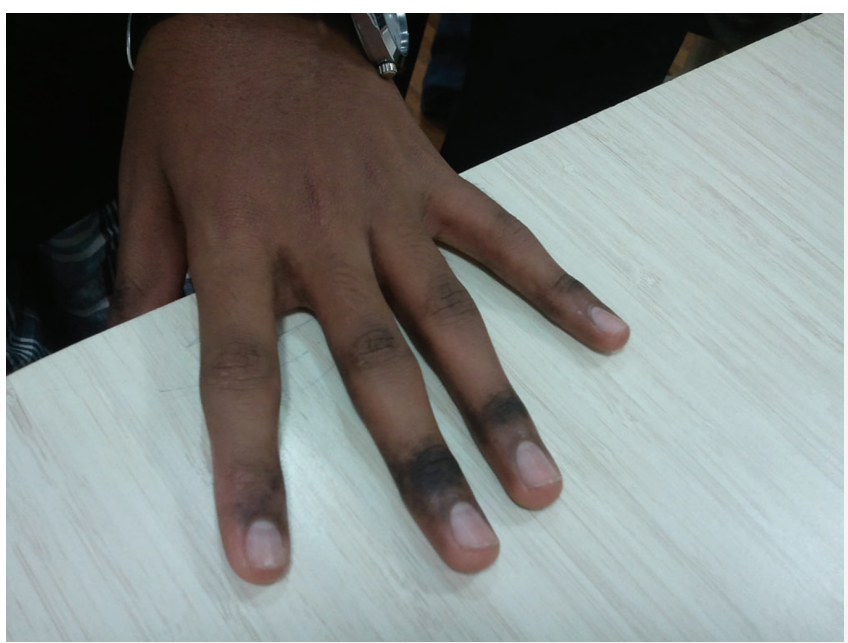

Figure 1. Macular hypermelanosis over dorsum of hand predominantly involving distal interphalangeal joints.

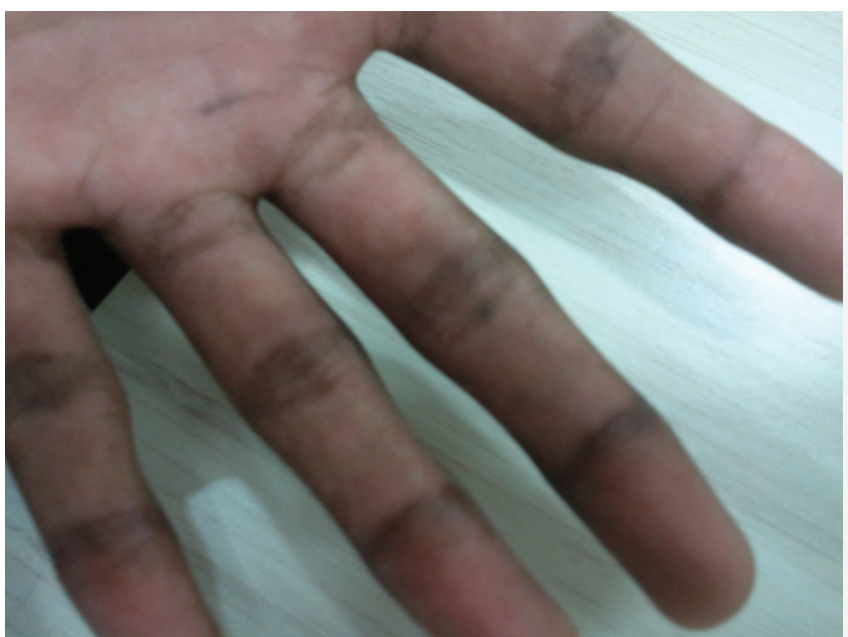

Figure 1. Macular hypermelanosis also involving the palmar aspect of the hand. 
Cutaneous pigmentation is also reported in patients with HIV (Human Immuno Deficiency) especially on zidovudine therapy [4,5]. However hypermelanosis associated with dengue fever is very rare. Common cutaneous lesions described in association with dengue fever include a transient generalized macular erythematous rash which blanches upon pressure during the initial phase of illness followed by a generalized confluent petechial rash with sparing of small islands of skin during the convalescent phase [6,7]. Thus occurrence of hyperpigmentation following dengue fever is an extremely rare phenomenon and to the best of our knowledge no such case till now has been reported.

\section{REFERENCES}

1. Dominguez-Soto L, Hojyo-Tomoka T, Vega-Memije E, Arenas R, Cores-Franco R. Pigmentary problems in the Tropics. Dermatol Clin. 1994;12:777-84.
2. Dereure O. Drug-induced skin pigmentation. Epidemiology, diagnosis and treatment. Am J Clin Dermatol. 2001;2:253-62.

3. Bhat RM, Rai Y, Ramesh A, Nandakishore B, Sukumar D, Martis $\mathrm{J}$, et al. Mucocutaneous manifestations of chikungunya fever: A study from an epidemic in coastal Karnataka. Indian J Dermatol. 2011;56:290-4.

4. Gallais V, Lacour JP, Perrin C, Ghanem G, Bodokh I, Ortonne JP. Acral hyperpigmented macules and longitudinal melanonychia in AIDS patients. Br J Dermatol. 1999;126:387-91.

5. Satyendra Kumar Singh, Tulika Rai. A case of zidovudine induced pigmentation on palms and soles. Indian Dermatol Online J. 2014;5:98-9.

6. Thomas EA, John M, Bhatia A. Cutaneous manifestations of dengue viral infection in Punjab (north India). Int J Dermatol. 2007;46:715-9.

7. Inamadar AC, Palit A, Sampagavi VV, Raghunath S, Deshmukh NS. Cutaneous manifestations of chikungunya fever: Observations made during a recent outbreak in south India. Int J Dermatol 2008;47:154-9. 